\title{
Article \\ Relationships between Muscle Architecture and Performance in Division I Male Italian Field Hockey Players
}

\author{
Sandro Bartolomei ${ }^{1, *}{ }^{\oplus}$, Federico Nigro ${ }^{2}$, Simone Ciacci ${ }^{1} \oplus$, Ivan Malagoli Lanzoni ${ }^{2} \oplus$, Filippo Treno $^{3}$ \\ and Matteo Cortesi ${ }^{2}$ iD \\ 1 Department of Biomedical and Neuromotor Sciences, University of Bologna, 40100 Bologna, Italy; \\ simone.ciacci@unibo.it \\ 2 Department for Life Quality Studies, University of Bologna, 40100 Bologna, Italy; \\ federico.nigro2@unibo.it (F.N.); ivan.malagoli@unibo.it (I.M.L.); m.cortesi@unibo.it (M.C.) \\ 3 National Field Hockey Technical Committee, 00196 Rome, Italy; filippotreno@libero.it \\ * Correspondence: sandro.bartolomei@unibo.it; Tel.: +39-051-2088779
}

check for

updates

Citation: Bartolomei, S.; Nigro, F.; Ciacci, S.; Malagoli Lanzoni, I.; Treno, F.; Cortesi, M. Relationships between Muscle Architecture and Performance in Division I Male Italian Field Hockey Players. Appl. Sci. 2021, 11, 4394. https://doi.org/10.3390/ app11104394

Academic Editors: Nikolaos Zaras and Spyridon Methenitis

Received: 30 March 2021

Accepted: 11 May 2021

Published: 12 May 2021

Publisher's Note: MDPI stays neutral with regard to jurisdictional claims in published maps and institutional affiliations.

Copyright: (c) 2021 by the authors. Licensee MDPI, Basel, Switzerland. This article is an open access article distributed under the terms and conditions of the Creative Commons Attribution (CC BY) license (https:/ / creativecommons.org/licenses/by/ $4.0 /)$.

\begin{abstract}
Muscle architecture has been proposed as one of the most important determinants of muscle strength and power performance. The purpose of the present investigation was to correlate the muscle architecture with power, agility and maximal strength in Italian division I Field Hockey (FH) players. Twenty players (age $=25.4 \pm 5.2 \mathrm{y}$; body mass $=78.5 \pm 9.0 \mathrm{~kg}$; body height $=179.6 \pm 7.8 \mathrm{~cm}$ ) were assessed for body composition, agility, sprint and maximal isometric force in squat (ISQ). The pro-agility test (PRO) and 30-m sprint (SPRINT) were used for agility and speed assessments, respectively. In addition, the pennation angle (PA), fascicle length (FL) and muscle thickness (MT) of the vastus lateralis were assessed via B-mode ultrasound. Large positive correlations were found between PRO and both PA and MT ( $\mathrm{r}=0.62 ; p=0.006$ and $\mathrm{r}=0.51 ; p=0.032$, respectively). Moreover, SPRINT was positively correlated with PA and negatively correlated with FL $(r=0.50, p=0.046$; and $r=-0.50 ; p=0.034$, respectively). Large positive correlations were also detected between body fat and both PRO and SPRINT ( $\mathrm{r}=0.58 ; p=0.012$ and $\mathrm{r}=0.61 ; p=0.009$, respectively), indicating detrimental effects of the body fat on specific performances. The present findings showed the existence of large relationships between the muscle architecture of the vastus lateralis and physical characteristics related to elite performance in FH. Low PA and long FL of the vastus lateralis appear important parameters for agility and sprint performances.
\end{abstract}

Keywords: vastus lateralis; muscle morphology; agility; sprint

\section{Introduction}

Field Hockey $(\mathrm{FH})$ is a field-invasive game that requires a good combination of aerobic fitness, anaerobic power, and technical skills [1,2]. In addition, agility represents a key factor for the development of technical skills such as dribbling or defensive drills. Agility can be defined as the quickness by which an athlete can change direction and includes complete decelerations and quick accelerations [3]. Despite the importance of this element in FH, interestingly, no significant differences in agility and sprint performances were detected between division I and division II Italian players [4].

Muscle architecture has been proposed as one of the most important determinants of muscle performance [5]. Some studies reported significant correlations $(r=0.51-0.71)$ between the muscle morphology of the vastus lateralis and dynamic performances such as a $100 \mathrm{~m}$ sprint [6] or sprint performance on a non-motorized treadmill [7]. Significant correlations $(r=0.54)$ have been also detected between the muscle morphology of the gastrocnemius and the sprint performance in competitive sprinters [8]. Furthermore, significant correlations were found between the muscle morphology of the vastus lateralis and the isokinetic torque expressed at high angular velocity $(r=0.55)$ [9], and between the muscle thickness of the pectoral muscle and the bench press 1 repetition maximum 
(1RM; $r=0.83)$ [10]. Despite muscle size significantly influences muscle strength [11], other parameters such as the pennation angle (PA) and fascicle lengths (FL) appear more related to dynamic performances and power [5]. Indeed, large correlations have been reported between the sprint abilities and the FL of the vastus lateralis (VL) in sprinters [8]. In addition, greater FL and lower PA have been measured in Australian Football Players compared to endurance athletes [12]. Furthermore, Zaras et al. [13] reported large correlations between the muscle thickness (MT) and FL of VL and the peak rate of force development ( $\mathrm{pRFD}$ ) produced at an isometric leg press by young male and female track and field throwers. Finally, Nasirzade et al. [14] showed large correlations between the front crawl sprint swimming performance and the FL of the vastus lateralis in young swimmers. Even though several investigations underlined the role of both FL and PA for dynamic performances in several sports, surprisingly, to the best of our knowledge, only one study to date investigated the relationships between agility and muscle architecture of VL [15]. Those authors reported negative correlations between PA and agility performance, while no correlations were detected between FL and agility in badminton players.

To date, no studies have investigated the relationships between muscle architecture and maximal strength, power and agility performances in FH players. Thus, the aim of the present investigation was to study the relationships between muscle architecture of VL and athletic performance in high-level FH players. Further information on the relationships between muscle morphology and dynamic performances (including agility), may represent a step further toward a better understanding of the relationships between muscle architecture and performance in competitive athletes.

\section{Materials and Methods}

\subsection{Subjects}

Twenty high-level male FH players (age $=25.4 \pm 5.2 \mathrm{y}$; body mass $=78.5 \pm 9.0 \mathrm{~kg}$; body height $=179.6 \pm 7.8 \mathrm{~cm}$; body fat $=12.4 \pm 3.1 \%$ ) participated in the present study. All the players were white Europeans, playing in the division I Italian FH championship. Inclusion criteria required participants to be between the ages of 18 and 35 years and have played at least 8 games at the national senior level in the 24 months prior to the tests. In addition, participants were required to be involved in specific training for Field Hockey at least three times per week and in resistance training at least one time per week in the three years previous to the investigation. The average training frequency was $4.1 \pm 1.6$ training sessions per week. Exclusion criteria included injuries occurred in the year prior to the study and doping-related disqualifications occurred in the three years prior to the study. Participants were asked to abstain from alcohol, caffeine and resistance training for at least $24 \mathrm{~h}$ prior to the tests. The study was approved by the University of Bologna Institutional Review Board. Testing procedures were fully explained to each participant before obtaining individual written informed consent.

\subsection{Measures}

Anthropometric Characteristics. The body mass, body height and body composition were assessed prior to the standardized warm-up. The body height was measured using a fixed stadiometer while the body mass was measured at nearest of $0.1 \mathrm{~kg}$ using a weight scale (Seca 769; Hamburg, Germany). The body composition was tested using a skinfold caliper (Lange; Cambridge Scientific Industries, Cambridge, MD, USA). The body fat percentage was calculated using the 3-site methods of Evans et al. [16].

Ultrasound assessments. Non-invasive skeletal muscle ultrasound images were collected from the participant's right thigh. Prior to image collections, all anatomical locations of interest were identified using standardized landmarks for the VL. The landmark for the VL was identified along its longitudinal distance at 50\% from the proximal insertion of the muscle. The length of the VL encompassed the distance from the lateral condyle of the tibia to the most prominent point of the greater trochanter of the femur. VL measurement required the participants to lay on their side on the examination table for a minimum 
of $15 \mathrm{~min}$ before images were collected. The same investigator performed all landmark measurements for each participant.

A $12 \mathrm{MHz}$ linear probe scanning head (Echo Wave 2, Telemed Ultrasound Medical System, Milan, Italy) was coated with water soluble transmission gel to optimize the spatial resolution and used to collect all ultrasound images. The probe was positioned on the surface of the skin without depressing the dermal layer and the view mode (gain $=50 \mathrm{~dB}$; image depth $=5 \mathrm{~cm}$ ) was used to take panoramic pictures of the VL. During the measurements, the participants were asked to relax their leg muscles and maintain the left lateral decubitus position. Legs were positioned together, with a $10^{\circ}$ bend angle in the knees [17]. All images were collected and transferred to a personal computer. All ultrasound images were taken and analyzed by the same technician. The muscle thickness and PA were quantified in still images using the measuring features of the ultrasound device. The muscle thickness was determined as the distance between the subcutaneous adipose tissue-muscle interface and the intermuscular interface, and the PA was determined as the angle between the echoes of the deep aponeurosis of the muscle and the echoes from interspaces among the fascicles. The fascicle length was calculated from MT and PA using the following equation [8]:

$$
\mathrm{FL}=\mathrm{MT} \times \mathrm{SIN}(\mathrm{PA})^{-1}
$$

The intra-class correlation coefficients (ICCs) were $0.96(\mathrm{SEM}=0.63 \mathrm{~mm}), 0.93\left(\mathrm{SEM}=1.1^{\circ}\right)$ and $0.96(\mathrm{SEM}=8.0 \mathrm{~mm})$ for PMT, PA and FL, respectively.

Strength and power assessments. A countermovement jump test (CMJ) was performed using a contact mat (Globus Ergo Jump, Codognè, Italy) to measure the flight time. The jump height was calculated using the following equation [18]: $9.81 \times$ flight $\operatorname{time}^{2} / 8$. The participants performed two jumps with a 3-min rest between each jump. They were required to keep their hands on their hips while jumping and were asked to maximize their jump height. The intraclass coefficient calculated for the CMJ was $0.96(\mathrm{SEM}=100.3 \mathrm{~W})$.

An isometric squat test (ISQ) was performed using an adjustable rack that permitted fixation of the bar at appropriate height while the participants were standing on a force plate (Kistler, Winterthur, Switzerland, $500 \mathrm{~Hz}$ ). The isometric parallel squat was performed with knee and hips at the same height. The participants were required to perform two maximal 6-s isometric muscle actions with a 3-min recovery time between each attempt. The peak force was measured and the peak rate of force development was calculated using a 20-ms window (pRFD20), as previously described by Haff, Ruben, Lider, Twine, and Cormie [19].

The intraclass coefficients were $0.85(\mathrm{SEM}=130.7 \mathrm{~N})$ and $0.51\left(\mathrm{SEM}=1010.3 \mathrm{~N} \mathrm{~s}^{-1}\right)$ for ISQ and pRFD20, respectively. During all isometric and isokinetic measurements, the participants were verbally encouraged by the study investigators. In addition, to avoid any possible ergogenic effect [20], they were not allowed to listen to music during the assessment session.

Sprint and agility assessments. The sprint performance was tested by a 30-m dash. The participants began from a standing position with a self-start. The pro-agility test (PRO) was performed as measurements of agility skills. A 3-min recovery time was used between the trials. In both assessments, the time was measured at the nearest $0.01 \mathrm{~s}$ using two couples of time lights (Globus Ergo Tester, Codognè, Italy). The intraclass coefficient calculated for the PRO was $0.97($ SEM $=0.05 \mathrm{~s})$.

\subsection{Design and Procedures}

Testing procedures were fully explained to each participant before obtaining individual written informed consent. The participants were assessed following the first 2 games of the 2018 outdoor season, after $48 \mathrm{~h}$ of rest. The timeline of the assessments performed is reported in Figure 1. Anthropometric evaluations and muscle ultrasound measurements were performed prior to the performance assessments. A standardized warm-up [4] consisting of 5 min jogging, 10 body weight squats, 10 body weight walking lunges, $10 \mathrm{dy}-$ namic walking hamstring stretches, 10 dynamic walking quadriceps stretches, and 10 body 
weight push-ups was performed before the performance evaluations. Subsequently, each participant was tested for maximal isometric force, agility and sprinting performance.

\begin{tabular}{|c|c|c|c|c|c|c|}
\hline $\begin{array}{c}\text { Anthropometric } \\
\text { measurements }\end{array}$ & $\begin{array}{c}\text { Ultrasound } \\
\text { assessments }\end{array}$ & Warm-Up & CMJ & ISQ & PRO & SPRINT \\
\hline
\end{tabular}

Figure 1. Timeline of the assessments performed. $\mathrm{CMJ}=$ countermovement jump; ISQ = isometric squat; PRO = pro-agility test; SPRINT = 30-m dash sprint.

All the assessments were supervised by certified investigators (Ph.D. in sport science). Agility and running assessments were performed on a synthetic water-based FH surface, recording ambient temperature, humidity and wind condition. The estimated sample size was 15 to detect significant correlations between anthropometric, morphological parameters and performance.

\subsection{Statistical Analysis}

All data are reported as mean \pm standard deviation (SD). The normal distribution of the data was assessed using a Shapiro-Wilk test. The Pearson product moment correlations were used to examine relationships between the different examined variables. According to Hopkins, Marshall, Batterham, \& Hanin [21], the correlation coefficients ( $r$ ) of 0.1, 0.3, $0.5,0.7$ and 0.9 were interpreted as small, moderate, large, very large and extremely large relationship, respectively. The statistical analysis was performed using SPSS version 25 (Chicago, IL, USA). The significance was set at an alpha level of $p \leq 0.05$.

\section{Results}

Measurements of anthropometric and performance parameters and measurements of the muscle architecture of the VL are reported in Tables 1 and 2, respectively. Correlations between the different parameters are reported in Table 3. In addition, typical ultrasound images of the VL are reported in Figure 2. Large correlations were detected between PA and both PRO $(\mathrm{r}=0.62 ; p=0.006)$ and SPRINT time $(\mathrm{r}=0.50 ; p=0.046)$. A large correlation was also detected between MT and PRO $(r=0.51 ; p=0.032)$. A large negative correlation was detected between FL and SPRINT time $(\mathrm{r}=-0.50 ; p=0.034)$.

Table 1. Anthropometric and performance parameters. ISQ = isometric squat; $\mathrm{pRFD} 20=$ peak rate of force development; PRO = pro-agility test.

\begin{tabular}{cc}
\hline Performance Parameters & M \pm SD (Min-Max) \\
\hline Body Mass $(\mathrm{kg})$ & $78.5 \pm 9.0(58.1-89.5)$ \\
Body Height $(\mathrm{cm})$ & $179.6 \pm 7.8(160.1-185.3)$ \\
Body Fat $(\%)$ & $12.4 \pm 3.1(8.4-19.0)$ \\
ISQ (N) & $1233.4 \pm 242.0(921.5-1828.7)$ \\
pRFD20 (N/sec $\left.{ }^{-1}\right)$ & $6915.6 \pm 1152.2(5175.0-9046.1)$ \\
CMJ (cm) & $41.9 \pm 4.2(34.0-50.2)$ \\
PRO (s) & $4.7 \pm 0.2(4.4-5.1)$ \\
SPRINT (s) & $4.3 \pm 0.2(4.0-4.6)$ \\
\hline
\end{tabular}

Table 2. Parameters of muscle architecture of vastus lateralis (VL). MT = muscle thickness; PA = pennation angle; $F L=$ fascicle length.

\begin{tabular}{cc}
\hline Muscle Architecture & M (SD) \\
\hline MT (mm) & $17.2 \pm 3.5$ \\
$\operatorname{PA~}\left(^{\circ}\right)$ & $10.6 \pm 1.9$ \\
$\operatorname{FL~}(\mathrm{mm})$ & $94.7 \pm 16.5$ \\
\hline
\end{tabular}


Table 3. Correlations between the different parameters of performance and muscle morphology. $\mathrm{ISQ}=$ isometric squat; $\mathrm{CMJ}=$ countermovement jump; $\mathrm{PRO}=$ pro-agility; $\mathrm{SPRINT}=30$-m sprint; $\mathrm{MT}=$ muscle thickness; $\mathrm{PA}=$ pennation angle; $\mathrm{FL}=$ fascicle length.

\begin{tabular}{|c|c|c|c|c|c|c|c|}
\hline & ISQ & $\mathrm{CMJ}$ & PRO & SPRINT & MT & PA & FL \\
\hline Body Fat & $\begin{array}{c}0.13 \\
p=0.602\end{array}$ & $\begin{array}{c}0.40 \\
p=0.119\end{array}$ & $\begin{array}{c}0.58 \\
p=0.012\end{array}$ & $\begin{array}{c}0.61 \\
p=0.009\end{array}$ & $\begin{array}{c}0.21 \\
p=0.408\end{array}$ & $\begin{array}{c}0.37 \\
p=0.126\end{array}$ & $\begin{array}{c}-0.11 \\
p=0.664\end{array}$ \\
\hline ISQ & & $\begin{array}{c}0.46 \\
p=0.071\end{array}$ & $\begin{array}{c}-0.14 \\
p=0.574\end{array}$ & $\begin{array}{c}-0.57 \\
p=0.013\end{array}$ & $\begin{array}{c}0.38 \\
p=0.118\end{array}$ & $\begin{array}{c}0.09 ; \\
p=0.732\end{array}$ & $\begin{array}{c}0.30 \\
p=0.217\end{array}$ \\
\hline $\mathrm{CMJ}$ & & & $\begin{array}{c}-0.46 \\
p=0.108\end{array}$ & $\begin{array}{c}-0.33 \\
p=0.208\end{array}$ & $\begin{array}{c}-0.18 \\
p=0.496\end{array}$ & $\begin{array}{c}-0.20 \\
p=0.447\end{array}$ & $\begin{array}{c}-0.09 \\
p=0.739\end{array}$ \\
\hline PRO & & & & $\begin{array}{c}0.43 \\
p=0.073\end{array}$ & $\begin{array}{c}0.51 \\
p=0.031\end{array}$ & $\begin{array}{c}0.62 \\
p=0.006\end{array}$ & $\begin{array}{c}0.06 \\
p=0.801\end{array}$ \\
\hline SPRINT & & & & & $\begin{array}{c}0.53 \\
p=0.845\end{array}$ & $\begin{array}{c}0.50 \\
p=0.046\end{array}$ & $\begin{array}{c}-0.50 \\
p=0.034\end{array}$ \\
\hline MT & & & & & & $\begin{array}{c}0.53 \\
p=0.022\end{array}$ & $\begin{array}{c}0.57 \\
p=0.014\end{array}$ \\
\hline PA & & & & & & & $\begin{array}{c}-0.37 \\
p=0.127\end{array}$ \\
\hline
\end{tabular}
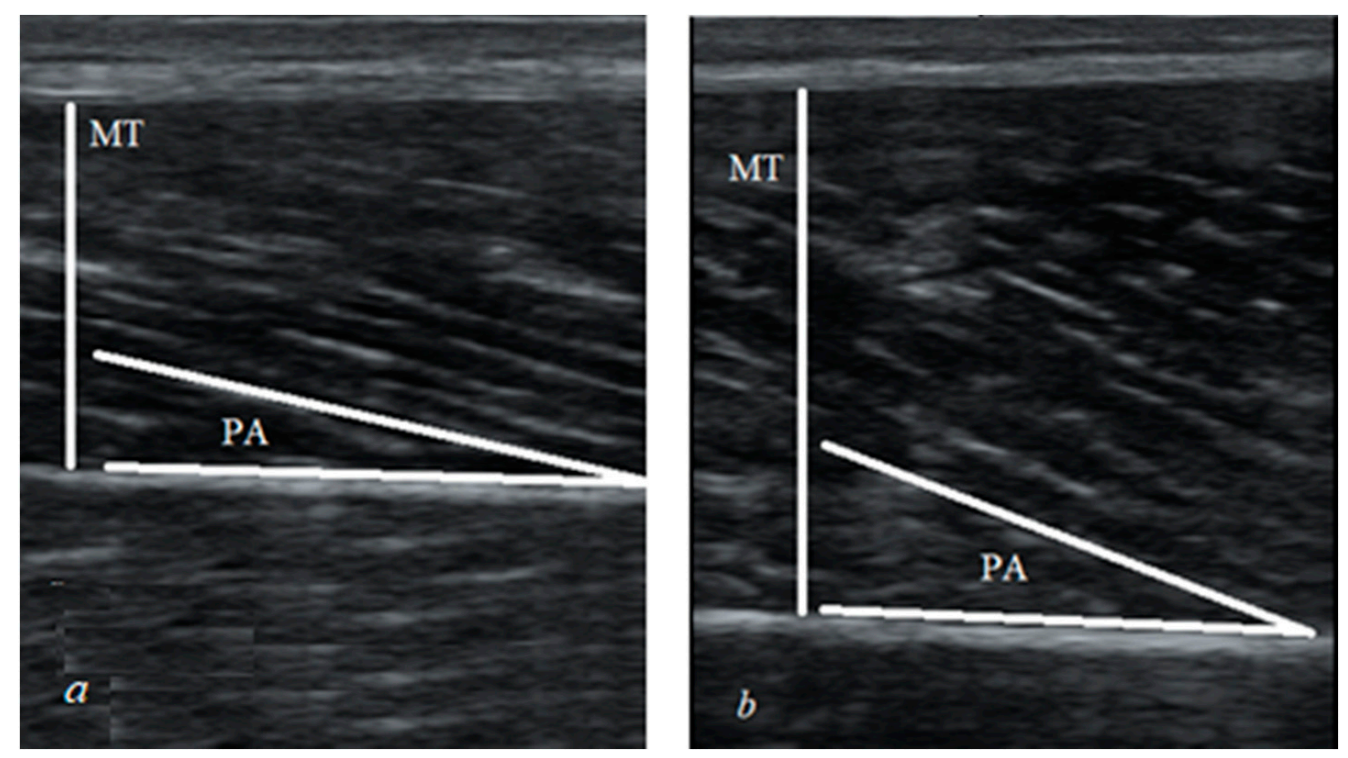

Figure 2. Ultrasound images of the VL (vastus lateralis) of two participants. Subject $a$ and subject $b$ were characterized by different MT and PA. MT = muscle thickness; PA = pennation angle.

The results of the performance assessments are shown in Table 2 and the correlations between the variables are reported in Table 3. The body fat was largely correlated with PRO $(r=0.58 ; p=0.012)$ and SPRINT $(r=0.61 ; p=0.009)$. In addition, a negative correlation was found between ISQ and SPRINT $(r=-0.57 ; p=0.013)$. No significant correlation was observed between ISQ and CMJ and any parameter of the muscle architecture. The scatter plots of PA and PRO, PA and SPRINT, Body Fat and PRO and Body Fat and SPRINT are shown in Figures 3-6, respectively. 


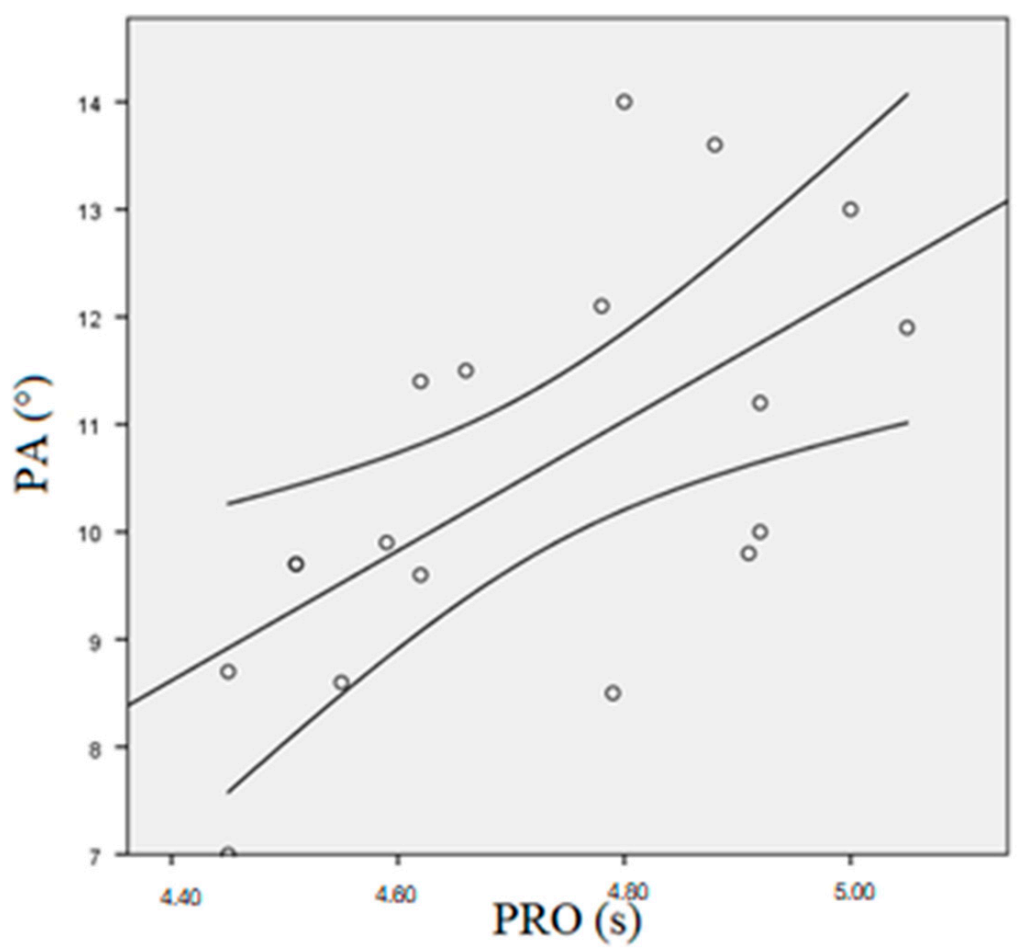

Figure 3. Scatter plot between PA of VL and PRO. PA = pennation angle. PRO = pro-agility test. The middle line represents the median and the parabolic lines represent the $95 \%$ confidence interval.



Figure 4. Scatter plot between PA of VL and 30-m Sprint. PA = pennation angle. The middle line represents the median and the parabolic lines represent the $95 \%$ confidence interval. 


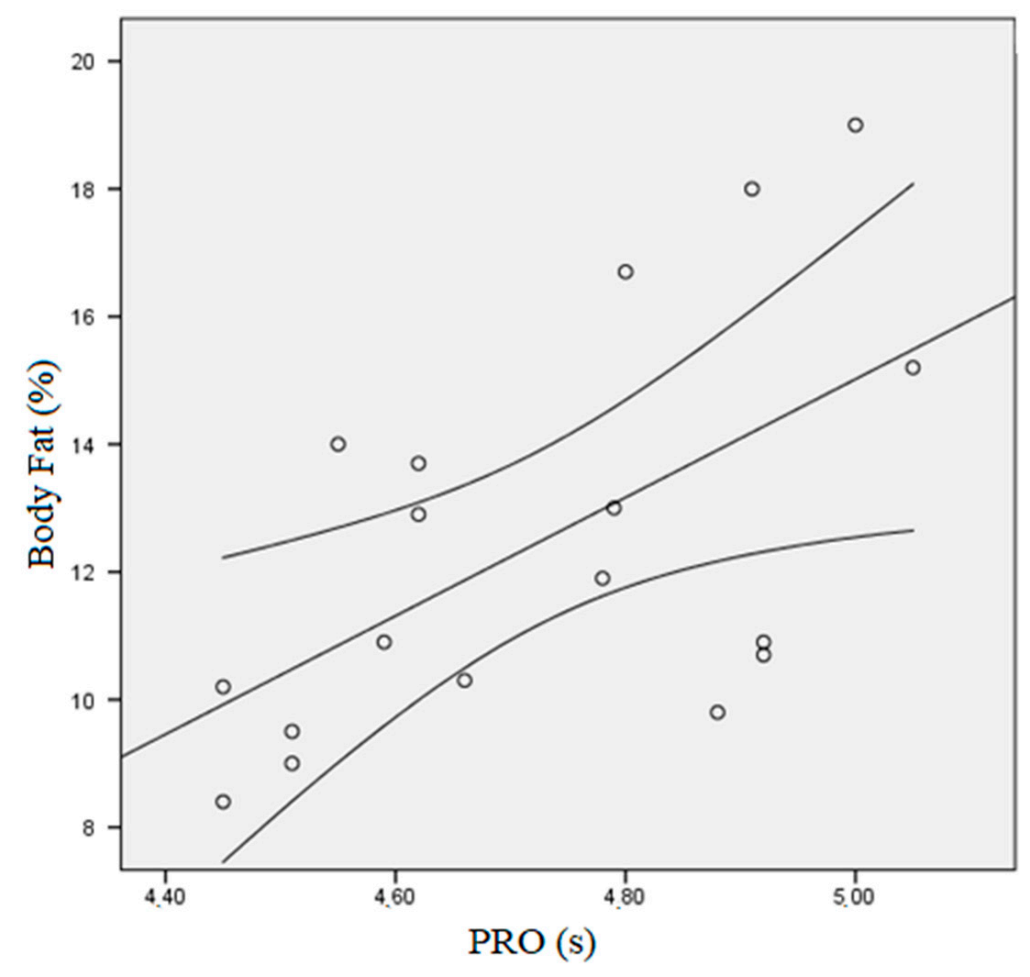

Figure 5. Scatter plot between Body Fat and PRO. PRO = pro-agility test. The middle line represents the median and the parabolic lines represent the $95 \%$ confidence interval.

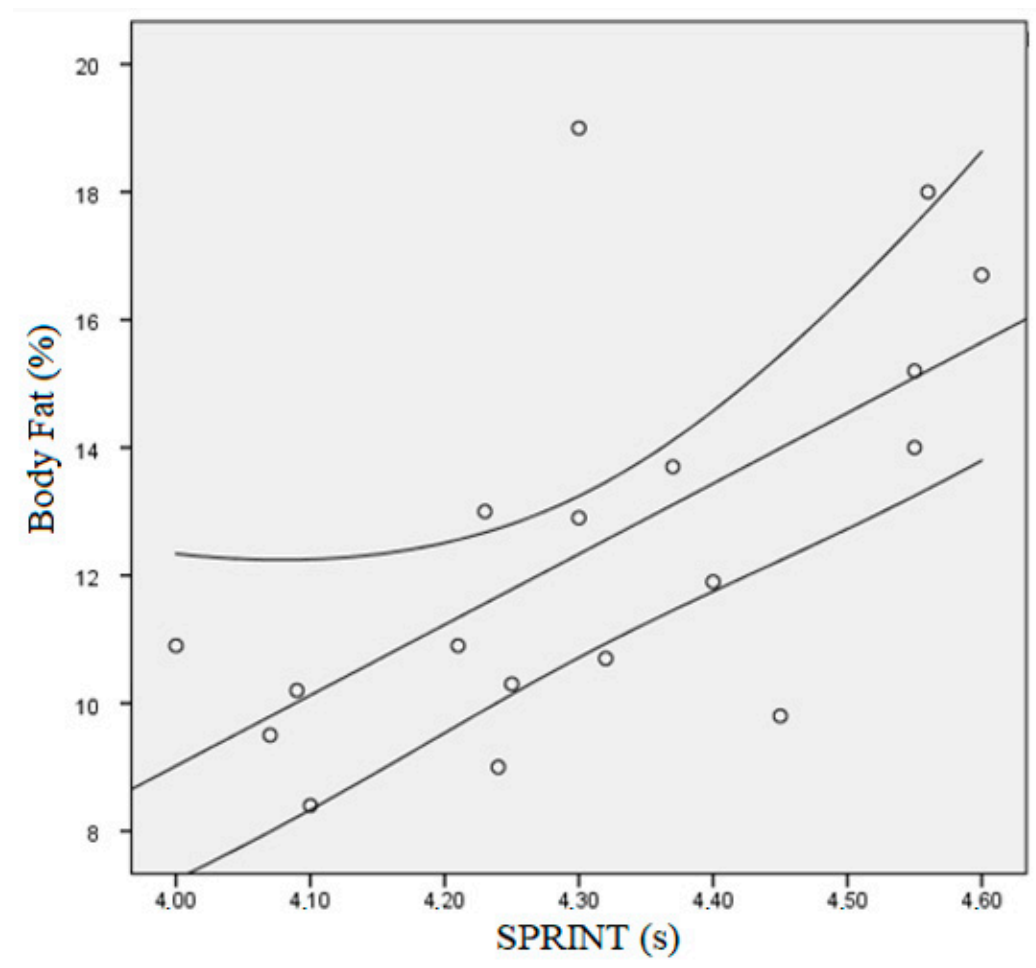

Figure 6. Scatter plot between Body Fat and 30-m Sprint. The middle line represents the median and the parabolic lines represent the $95 \%$ confidence interval.

\section{Discussion}

The results of the present investigation showed significant relationships between the muscle architecture and the muscle performance in high-level FH players. In particular, the FL of the VL were correlated with the 30-m sprint performance. This is consistent with 
Abe et al. [6] and Kumagai et al. [8] who reported significant associations between FL of VL and the sprint performance in both female and male sprinters. Muscle FL has been suggested to play an important role in determining the maximum contraction velocity of the muscle [22] and consequently the maximum sprint ability [23]. Indeed, longer fascicles warranted higher contraction speeds through a greater number of sarcomeres in series than shorter FL [24]. The present investigation also showed a significant correlation between the PA and both sprint and agility performances. Greater PA may allow to attach more contractile tissue to a given area of tendon [25] but it may negatively affect the contraction speed [24]. On the contrary, smaller PA and relatively higher FL may represent an advantage for power and speed performance [6]. Increased PA and reduced FL have been reported in trained individuals following resistance training programs [26,27]. On the contrary, increases in FL and reductions in PA were obtained in competitive athletes of both sexes following a 5-week training program including both resistance and sprint/jump training [25]. Both FH conditioning and games included several different stimuli such as changes of direction and sprint that may alter the muscle morphology. In addition, all the participants in the present study performed at least 2 resistance training sessions per week in the last 2 years. As reported by Blazevitch et al. [25], the concurrent action of resistance training and power/speed activities may lead to significant changes in the muscle architecture. To date, only one study investigated the relationships between muscle architecture and agility [15], and no significant correlations between MT, PA or FL of VL and the agility t-test were found. The agility $t$-test, however, does not include only changes of direction and sprint, but also lateral shuffles and backward running that are influenced by the individual motor coordination. The presence of these movements may have reduced the correlation between the agility performance and the muscle morphology.

No significant correlations have been detected between MT and maximal strength. Despite the muscle dimension represents a determinant factor for maximal force production, VL may not be the most important portion of quadriceps for maximal force production in the squat exercise. Furthermore, the lack of significant correlation with both maximal force and pRFD and a low level of intraclass correlation for pRFD20 may be due to a short familiarization phase preceding the ISQ assessment.

The main limitation of the present investigation was represented by the insufficient familiarization of the participants to the strength and power assessments performed. In particular, FH players participating in the study were not completely accustomed to the ISQ test.

The pro-agility test has been extensively used among different populations of athletes. Normative data were presented for NCAA Division I College Basketball, Baseball or American Football [28]. The 90-percentile performances of $4.22 \mathrm{~s}, 4.25 \mathrm{~s}$ and $4.21 \mathrm{~s}$ were reported for Basketball, Baseball and American Football players, respectively. The pro-agility test was also included in the NFL and 90-percentile performances between 3.89 and 4.45 were reported for defensive back and offensive linemen players, respectively. Yamashita, Asakura, Ito, Yamada, and Yamada [29] reported a mean time of $4.20 \mathrm{~s}$ and $4.62 \mathrm{~s}$ for running backs and offensive line men NFL players, respectively. The mean performance of the participants in the present study was $4.73 \mathrm{~s}$. Despite the importance of agility in FH, to the best of our knowledge, no normative data exist for high-level players. The differences between the agility performance in Italian Division I players and the performance of several high-level sport populations may indicate a different approach to talent selection and training. In particular, the training process in FH may be more focused on technical skills than on physical development. In the present investigation, the results in SPRINT are in line with the performances previously measured on Italian Division I FH players [30]. In the present investigation, no correlations were found between CMJ and any other assessment. Even if plyometric exercises are often performed by high-level $\mathrm{FH}$ players, a vertical jump does not represent a typical skill in FH and the participants may not be accustomed enough to this assessment. Significant correlations between the body fat and the time on a 30-m dash confirms the relationship between body composition on sprint 
performance [31]. Furthermore, the agility performance appears negatively correlated with the body fat. Other studies [32] reported lower levels of body fat in professional soccer players compared to the present findings $(9.6 \%$ vs. $12.4 \%$ in professional soccer players and in Italian Field Hockey players, respectively). Lower percentages of fat mass, however, were also detected in previous investigations conducted on division I Italian Field Hockey players [30]. Excess fat may impair general locomotion and performance in Field Hockey. This includes intermittent sprinting, cruising and changes of direction [33]. Field Hockey is a non-professional sport in Italy and generalized team sessions usually represent the main part of the training. However, additional workouts, that consider the principles of individualization and specificity, may be crucial to improve sport-specific physical components and, if necessary, to reduce the fat mass in Field Hockey players.

\section{Conclusions}

In conclusion, the present study has shown the various relationships existing between the muscle architecture of the VL and selected physical characteristics such as agility and sprint in high-level Italian FH players. Smaller PA and higher FL of the VL may be important factors for sport-specific physical performances such as agility and sprint. Correlations between the muscle architecture of the VL and dynamic performances may indicate a potential role of specific morphological characteristics in reaching high performances in sports, such as Field Hockey, requiring high levels of speed and agility.

Although sport capacity generally consists of multiple components, researchers and coaches should be aware that the muscle architecture and anthropometric characteristics [34] may represent important parameters for talent identification. Indeed, B-mode ultrasound imaging of the VL may be included into assessment protocols to obtain additional information about the young athlete's future performance perspectives. Further investigations are needed to better understand the long-term effect of sport-specific training on muscle morphology.

Author Contributions: Conceptualization: S.B., F.T.; methodology: S.B., M.C.; investigation: S.B., F.N., I.M.L., F.T.; data curation: S.C., I.M.L.; writing: S.B., M.C., S.C.; review and editing: I.M.L., M.C.; supervision: S.C., M.C. All authors have read and agreed to the published version of the manuscript.

Funding: This research received no external funding.

Institutional Review Board: The study was conducted according to the guidelines of the Declaration of Helsinki, and approved by the Institutional Review Board (or Ethics Committee) of the University of Bologna (protocol code 46864; 28 April 2017).

Informed Consent Statement: Informed consent was obtained from all subjects involved in the study.

Data Availability Statement: the data presented in this study are available on request from the corresponding author.

Conflicts of Interest: The authors declare no conflict of interest.

\section{References}

1. Boyle, P.M.; Mahoney, C.A.; Wallace, W.F. The competitive demands of elite male field hockey. J. Sports Med. Phys. Fit. 1994, 34, 235-241.

2. Reilly, T.; Borrie, A. Physiology applied to field hockey. Sports Med. 1992, 14, 10-26. [CrossRef] [PubMed]

3. Mann, J.B.; Ivey, P.A.; Mayhew, J.L.; Schumacher, R.M.; Brechue, W.F. Relationship between agility tests and short sprints: Reliability and smallest worthwhile difference in National Collegiate Athletic Association Division-I football players. J. Strength Cond. Res. 2016, 30, 893-900. [CrossRef] [PubMed]

4. Bartolomei, S.; Hoffman, J.R.; Stout, J.R.; Merni, F. Effect of Lower-Body Resistance Training on Upper-Body Strength Adaptation in Trained Men. J. Strength Cond. Res. 2018, 32, 13-18. [CrossRef]

5. Blazevich, A.J.; Gill, N.D.; Zhou, S. Intra-and intermuscular variation in human quadriceps femoris architecture assessed in vivo. J. Anat. 2006, 209, 289-310. [CrossRef]

6. Abe, T.; Fukashiro, S.; Harada, Y.; Kawamoto, K. Relationship between sprint performance and muscle fascicle length in female sprinters. J. Physiol. Anthr. Appl. Hum. Sci. 2001, 20, 141-147. [CrossRef] 
7. Mangine, G.T.; Fukuda, D.H.; Townsend, J.R.; Wells, A.J.; Gonzalez, A.M.; Jajtner, A.R.; Bohner, J.D.; LaMonica, M.; Hoffman, J.R.; Fragala, M.S.; et al. Sprinting performance on the Woodway Curve 3.0 TM is related to muscle architecture. Eur. J. Sport Sci. 2015, 15, 606-614. [CrossRef]

8. Kumagai, K.; Abe, T.; Brechue, W.F.; Ryushi, T.; Takano, S.; Mizuno, M. Sprint performance is related to muscle fascicle length in male 100-m sprinters. J. Appl. Physiol. 2000, 88, 811-816. [CrossRef] [PubMed]

9. Bartolomei, S.; Rovai, C.; Lanzoni, I.M.; di Michele, R. Relationships Between Muscle Architecture, Deadlift Performance, and Maximal Isometric Force Produced at the Midthigh and Midshin Pull in Resistance-Trained Individuals. J. Strength Cond. Res. 2019. [CrossRef]

10. Bartolomei, S.; Grillone, G.; Di Michele, R.; Cortesi, M. A Comparison between Male and Female Athletes in Relative Strength and Power Performances. J. Funct. Morphol. Kinesiol. 2021, 6, 17. [CrossRef]

11. Fukunaga, T.; Miyatani, M.; Tachi, M.; Kouzaki, M.; Kawakami, Y.; Kanehisa, H. Muscle volume is a major determinant of joint torque in humans. Acta Physiol. Scand. 2001, 172, 249-255. [CrossRef]

12. Brughelli, M.; Cronin, J.; Nosaka, K. Muscle architecture and optimum angle of the knee flexors and extensors: A comparison between cyclists and Australian Rules football players. J. Strength Cond. Res. 2010, 24, 717-721. [CrossRef] [PubMed]

13. Zaras, N.D.; Stasinaki, A.N.E.; Methenitis, S.K.; Krase, A.A.; Karampatsos, G.P.; Georgiadis, G.V.; Spengos, K.M.; Terzis, G.D. Rate of force development, muscle architecture, and performance in young competitive track and field throwers. J. Strength Cond. Res. 2016, 30, 81-92. [CrossRef]

14. Nasirzade, A.; Ehsanbakhsh, A.; Ilbeygi, S.; Sobhkhiz, A.; Argavani, H.; Aliakbari, M. Relationship between sprint performance of front crawl swimming and muscle fascicle length in young swimmers. J. Sports Sci. Med. 2014, 13, 550. [PubMed]

15. Nadzalan, A.M.; Mohamad, N.I.; Lee, J.L.F.; Chinnasee, C. Relationship between muscle architecture and badminton-specific physical abilities. Hum. Mov. 2018, 19, 44-50. [CrossRef]

16. Evans, E.M.; Rowe, D.A.; Misic, M.M.; Prior, B.M.; Arngrímsson, S.A. Skinfold prediction equation for athletes developed using a four-component model. Med. Sci. Sports Exerc. 2005, 37, 2006-2011. [CrossRef] [PubMed]

17. Bemben, M.G. Use of diagnostic ultrasound for assessing muscle size. J. Strength Cond. Res. 2018, 16, 103-108.

18. Bosco, C.; Luhtanen, P.; Komi, P.V. A simple method for measurement of mechanical power in jumping. Eur. J. Appl. Physiol. Occup. Physiol. 1983, 50, 273-282. [CrossRef]

19. Haff, G.G.; Ruben, R.P.; Lider, J.; Twine, C.; Cormie, P. A comparison of methods for determining the rate of force development during isometric midthigh clean pulls. J. Strength Cond. Res. 2015, 29, 386-395. [CrossRef]

20. Bartolomei, S.; Di Michele, R.; Merni, F. Effects of self-selected music on maximal bench press strength and strength endurance. Percept. Mot. Ski. 2015, 120, 714-721. [CrossRef]

21. Hopkins, W.; Marshall, S.; Batterham, A.; Hanin, J. Progressive statistics for studies in sports medicine and exercise science. Med. Sci. Sports Exerc. 2009, 41, 3. [CrossRef] [PubMed]

22. Bodine, S.C.; Roy, R.R.; Meadows, D.A.; Zernicke, R.F.; Sacks, R.D.; Fournier, M.; Edgerton, V.R. Architectural, histochemical, and contractile characteristics of a unique biarticular muscle: The cat semitendinosus. J. Neurophysiol. 1982, 48, 192-201. [CrossRef] [PubMed]

23. Lee, S.S.; Piazza, S.J. Built for speed: Musculoskeletal structure and sprinting ability. J. Exp. Biol. 2009, 212, 3700-3707. [CrossRef] [PubMed]

24. Blazevich, A.J.; Giorgi, A. Effect of testosterone administration and weight training on muscle architecture. Med. Sci. Sports Exerc. 2001, 33, 1688-1693. [CrossRef] [PubMed]

25. Blazevich, A.J.; Gill, N.D.; Bronks, R.; Newton, R.U. Training-specific muscle architecture adaptation after 5-wk training in athletes. Med. Sci. Sports Exerc. 2003, 35, 2013-2022. [CrossRef] [PubMed]

26. Alegre, L.M.; Jiménez, F.; Gonzalo-Orden, J.M.; Martín-Acero, R.; Aguado, X. Effects of dynamic resistance training on fascicle length and isometric strength. J. Sport Sci. 2006, 24, 501-508. [CrossRef]

27. Kawakami, Y.; Abe, T.; Kuno, S.Y.; Fukunaga, T. Training-induced changes in muscle architecture and specific tension. Eur. J. Appl. Physiol. Occup. Physiol. 1995, 72, 37-43. [CrossRef]

28. Hoffman, J. Norms for Fitness, Performance, and Health; Human Kinetics: Champaign, IL, USA „, 2006; pp. $119-121$.

29. Yamashita, D.; Asakura, M.; Ito, Y.; Yamada, S.; Yamada, Y. Physical characteristics and performance of Japanese top-level American football players. J. Strength Cond. Res. 2017, 31, 2455. [CrossRef]

30. Bartolomei, S.; Nigro, F.; Gubellini, L.; Ciacci, S.; Merni, F.; Treno, F.; Cortesi, M.; Semprini, G. A physiological and sport-specific comparison between division I and division II Italian male Field Hockey players. J. Strength Cond. Res. 2019, 33, 3123-3128. [CrossRef]

31. Kano, Y.; Takahashi, H.; Morioka, Y.; Akima, H.; Miyashita, K.; Kuno, S.; Katsuta, S. Relationship between the morphological features of thigh muscles and sprinting performance. Med. Sci. Sports Exerc. 1997, 29, 220. [CrossRef]

32. Bandyopadhyay, A.; Datta, G.; Dey, S.K. Body composition characteristics and physiological performance tests of junior elite field hockey players according to different playing positions. J. Phys. Educ. Sport 2019, 19, 1460-1467.

33. Popovic, S.; Bjelica, D.; Jaksic, D.; Hadzic, R. Comparative Study of Anthropometric Measurement and Body Composition between Elite Soccer and Volleyball Players. Int. J. Morphol. 2014, 32, 267-274. [CrossRef]

34. Sharma, H.B.; Kailashiya, J. The anthropometric correlates for the physiological demand of strength and flexibility: A study in young indian field hockey players. J. Clin. Diagn Res. 2017, 11, CC01. [CrossRef] [PubMed] 